\title{
HUBUNGAN TINGKAT PENGETAHUAN DENGAN SIKAP REMAJA TERHADAP PENYALAHGUNAAN NAPZA DI SMA KATOLIK RANTEPAO
}

\author{
THE RELATIONSHIP BETWEEN KNOWLEDGE \\ LEVEL AND YOUTH ATTITUDES TOWARDS DRUG \\ ABUSE IN CATHOLIC HIGH SCHOOL RANTEPAO
}

Euis D. Komariah ${ }^{1}$, Nikodemus Sili Beda ${ }^{2}$

Keperawatan, STIK Stella Maris, Makassar ${ }^{1,2}$

\begin{abstract}
ABSTRAK
Masa remaja merupakan masa transisi, dimana pada masa ini remaja sedang mencari jati diri sebagai seorang remaja dan berusaha mencapai kemandirian dengan mengandalkan pengetahuan yang dimiliki untuk mencoba hal-hal yang baru yang terkadang menyimpang dari norma-norma masyarakat, oleh karena itu diharapkan remaja memiliki pengetahuan dan sikap yang baik untuk terhindar dari hal - hal yang negatif seperti penyalahgunaan NAPZA yang berdampak negatif baik secara fisik, psikologis, dan sosial. Tujuan penelitian ini adalah untuk mengetahui hubungan pengetahuan dan sikap remaja terhadap penyalahgunaan NAPZA di SMA Katolik disamakan Rantepao Toraja Utara. Peneltian ini dilakukan pada bulan Februari 2020. Jenis penelitian ini adalah korelasidengan pendekatan croos sectional. Populasi penelitian adalah semua siswa/i SMA Katolik disamakan Rantepao Toraja Utara dan teknik pengambilan sampel probabilty sampling dengan menggunakan pendekatan proportionate stratified random sampling, dengan jumlah sampel 100 responden. Pengumpulan data dengan menggunakan kuesioner. Uji statistik yang digunakan adalah uji statistik Chi Square dengan menggunakan uji alternatif Continuity correction dengan program SPSS. Dengan demikian, dapat ditarik kesimpulan bahwa tidak terdapat hubungan yang bermakna antara tingkat pengetahuan remaja dan sikap remaja terhadap penyalahgunaan NAPZA di SMA Katolik disamakan Rantepao Toraja Utara. Secara umum sikap ditentukan oleh pengetahuan, tetapi pola pikir, keyakinan dan emosi yang turut memegang peranan penting dalam menentukan sikap seseorang.
\end{abstract}

Kata Kunci: Pengetahuan, sikap, remaja dan NAPZA

\footnotetext{
ABSTRACT

Adolescence is a transitional period, where at this time adolescents are looking for identity as a teenager and trying to achieve independence by relying on their knowledge to try new things that sometimes deviate from society's norms. Therefore, it is hoped that adolescents have knowledge and a good attitude to avoid negative things such as drug abuse, which has a negative impact both physically, psychologically and socially. The purpose of this study was to determine the relationship between knowledge and attitudes of adolescents against drug abuse in Catholic High Schools equated to North Rantepao Toraja. This research was conducted in February 2020. This type of research is a correlation with the
} 
croos sectional approach. The study population was all Catholic high school students equal to Rantepao Toraja Utara and the sampling technique was probabilty sampling using a proportionate stratified random sampling approach, with a sample size of 100 respondents. Data collection using a questionnaire. The statistical test used is the Chi Square statistical test using the alternative test of Continuity correction with the SPSS. Thus, it can be concluded that there is no significant relationship between the level of knowledge of adolescents and adolescent attitudes towards drug abuse in Catholic High Schools compared to North Rantepao Toraja. In general, attitudes are determined by knowledge, but patterns of thought, beliefs and emotions play an important role in determining a person's attitude.

Keywords: Knowledge, attitudes, adolescents and drugs

\begin{tabular}{ll}
\hline Alamat Korespondensi & Jl. Maipa No.19, Losari, Kec. Ujung Pandang, Kota \\
& Makassar, Sulawesi Selatan 90113 \\
Email & $:$ reuisdedeh89@gmail.com
\end{tabular}

\section{PENDAHULUAN}

Remaja adalah sumber daya manusia yang merupakan komponen yang penting dalam pembangunan nasional. Hal ini dikarenakan remaja yang akan meneruskan pembangunan dan cita-cita bangsa. Oleh karena itu, perlu adanya perhatiah khusus pada remaja.

Masa remaja merupakan masa transisi, dimana pada masa masa seperti ini sering terjadi ketidakstabilan baik itu emosi maupun kejiwaan. Pada masa transisi ini juga remaja sedang mencari jati diri sebagai seorang remaja. Namun sering kali dalam pencarian jati diri ini remaja cenderung salah dalam bergaul sehingga banyak melakukan hal yang menyimpang dari norma-norma yang berlaku dimasyarakat salah satunya yaitu menyalahgunakan narkoba.

NAPZA adalah singkatan dari narkotika, alkohol, psikotropika, dan zat adiktif lainnya. NAPZA dapat berupa zat yang bila masuk ke dalam tubuh dan akan mempengaruhi tubuh, terutama susunan saraf pusat yang dapat menyebabkan gangguan pada fisik, psikis dan fungsi social (Sumiati, 2009). Para ahli sepakat bahwa secara garis besar ada tiga faktor yang mempengaruhi terjadinya penyalahgunaan NAPZA pada remaja yakni faktor narkobanya sendiri, faktor lingkungan, dan faktor individual yang berdampak pada kesehatan, ekonomi, sosial dan pendidikan, keamanan dan penegakan hukum (Afiatin, 2008).

Hasil survey yang diperoleh dari United Nation International Drug Control Program (UNDP), saat ini lebih dari 200 juta orang berusia 15-64 tahun di seluruh dunia telah menyalahgunakan narkoba yang terdiri dari: 160,9 juta orang (penyalahguna ganja), 34.1 juta orang (ATS), 13,7 juta orang (kokain), 15,9 juta orang (opiat), dan 10.6 juta orang (heroin). (Himapid UNHAS, 2009).

Di Indonesia sampai saat ini penyalahgunaan narkoba masih mengancam remaja meskipun Indonesia sudah berkomitmen bebas narkoba dan HIV AIDS pada tahun 2015. Ancaman tersebut terlihat dari jumlah pengguna narkoba dikalangan pelajar dan mahasiswa meningkat. Hal ini sebagaimana hasil penelitian yang dilakukan Badan Narkotika Nasional bekerja sama dengan Universitas Indonesia, penyalahgunaan narkoba di Indonesia sebesar 1,99\% atau sekitar 3,6 juta orang 
berumur 10-59 tahun. Tahun 2015, apabila tidak dilakukan upaya-upaya penanggulangan yang komprehensif, akan meningkat menjadi 2,8\% atau 5,1 juta orang (Cahyani, 2011).

Sedangkan di kota Makassar, Badan narkotika Makassar memaparkan bahwa estimasi jumlah pengguna narkoba di kota Makassar, mencapai 51.000 orang pecandu dengan usia pengguna didominasi oleh kalangan remaja. Angka ini juga yang menempatkan kota Makassar pada urutan ke 20 dalam pengguna obat terlarang dari 30 daerah yang disurvey di Indonesia (Makassar Tv, 2011). Hal ini disebabkan kota Makassar memiliki tingkat perekonomian tinggi yang menyebabkan peredaran narkoba juga mengalami peningkatan, di samping itu kota Makassar merupakan gerbang sindikat jaringan peredaran narkoba internasional untuk kawasan Indonesia timur (Tribun Timur, 2011).

Hasil penelitian yang dilakukan oleh Kurnia (2009) dengan judul "Hubungan tingkat pengetahuan remaja tentang NAPZA dengan kecenderungan penyalahgunaan NAPZA pada remaja kelas II di SMA Berbudi Yogyakarta" dengan jumlah responden 38 orang dapat disimpulkan bahwa 18 orang $(47,3 \%)$ memiliki tingkat pengetahuan yang baik, 12 responden $(31,5 \%)$ memiliki tingkat pengetahuan cukup, dan 8 responden $(21,2 \%)$ memiliki tingkat pengetahuan kurang. Responden yang mempunyai kecenderungan menolak NAPZA ada 30 responden (79\%), dan ragu-ragu ada 8 responden $(21 \%)$. Berdasarkan uji statistik dapat disimpulkan bahwa ada hubungan antara tingkat pengetahuan remaja tentang NAPZA dengan kecenderungan penyalahgunaan NAPZA pada responden.

SMA Katolik disamakan Rantepao merupakan salah satu sekolah swasta yang terletak di Toraja Utara yang merupakan Yayasan Paulus Makassar perwakilan Toraja. Jumlah murid yang terdapat pada sekolah tersebut sebanyak 452 orang yang berusia 15-17 tahun, dimana usia tersebut termasuk dalam kelompok remaja yang merupakan aset bangsa dikemudian hari. Seperti diketahui remaja memiliki sifat dinamis, energik, dan ingin tahu sehingga mudah terpengaruh pada hal-hal negatif salah satunya yaitu masalah penyalahgunaan NAPZA oleh karena itu remaja perlu memiliki pengetahuan untuk terhindar dari pengaruh negatif tersebut.

\section{METODE PENELITIAN}

Jenis penelitian termasuk penelitian Non-Eksperimental . Penelitian ini bersifat korelasi yaitu penelitian/penelahan hubungan antar 2 variabel pada suatu atau sekelompok subjek. Rancangan penelitian ini menggunakan pendekatan Cross Sectional yaitu merupakan rancangan penelitian dengan melakukan pengukuran atau pengamatan pada saat bersamaan sesuai dengan waktu yang ditentukan. (Hidayat, 2008).

Populasi dalam penelitian ini adalah seluruh siswa (i) SMA Katolik disamakan Rantepo yang berjumlah 452 orang yang terdiri dari kelas X 134 orang, kelas XI 178 orang dan XII 140 orang. Sementara itu sampel diambil dari semua siswa (i) SMA Katolik disamakan Rantepo. Dengan teknik pengambilan sampel penelitian yaitu probabilty sampling dengan menggunakan pendekatan proportionate stratified random sampling, dimana populasi mempunyai anggota yang tidak homogen, representatif. Penelitian ini dilakukan 14 Januari - 14 Februari 2020. 


\section{HASIL}

\section{HASIL DAN PEMBAHASAN}

Hasil Analisa Variabel

a. Analisa Univariat

1) Tingkat Pengetahuan

Dari penelitian yang telah dilaksanakan di SMA Katolik disamakan Rantepao Toraja Utara, 2012 menunjukkan bahwa dari 100 responden diperoleh data dengan tingkat pengetahuan cukup 71 responden $(71 \%)$ dan tingkat pengetahuan baik 16 responden (16\%). Hasil ini dapat dilihat pada tabel 5.4 berikut.

Tabel 5.4

Distribusi Frekuensi Berdasarkan Tingkat Pengetahuan Responden tentang NAPZA pada siswa/i kelas X, XI, XII SMA Katolik Disamakan Rantepao Toraja Utara, 2020.

\begin{tabular}{ccc}
\hline Pengetahuan & Frekuensi & Persentase (\%) \\
\hline Cukup+baik & 87 & 87 \\
Kurang & 13 & 13 \\
\hline Total & 100 & 100 \\
\hline
\end{tabular}

Sumber : Data Primer

2) Sikap

Dari penelitian yang telah dilaksanakan di SMA Katolik disamakan Rantepao Toraja Utara, 2012. Menunjukkan bahwa dari 100 responden diperoleh data dengan sikap baik 84 responden (84\%) dan sikap kurang 1 responden (1\%). Hasil ini dapat dilihat pada tabel 5.5 berikut.

\section{Tabel 5.5}

Distribusi Frekuensi Berdasarkan Sikap Responden terhadap penyalahgunaan NAPZA pada siswa/i kelas X, XI, XII SMA Katolik Disamakan Rantepao Toraja Utara, 2020.

\begin{tabular}{ccc}
\hline Sikap & Frekuensi & Persentase (\%) \\
\hline Cukup+baik & 99 & 99 \\
Kurang & 1 & 1 \\
\hline Total & 100 & 100 \\
\hline
\end{tabular}

Sumber : Data Primer

b. Analisa Bivariat

Dalam penelitian ini analisa bivariat dilakukan untuk mengetahui hubungan tingkat pengetahuan dan sikap remaja terhadap penyalahgunaan NAPZA di SMA Katolik disamakan Rantepao.

Dari hasil statistik dengan menggunakan uji statistikChi Square dengan uji alternative Continuity correction diperoleh nilai $\mathrm{X} 2$ hitung=1,223 dan $\mathrm{X} 2$ tabel $=3,841$. Hal ini menunjukkan nilai $\mathrm{X} 2$ hitung $<\mathrm{X} 2$ tabelmaka hipotesis nol (Ho) diterima dan Ha ditolak berarti tidak ada hubungan yang bermakna antara tingkat pengetahuan dan sikap 
Bali Medika Jurnal.

Vol 7 No 2, 2020: 245-252

ISSN : 2615-7047

DOI: https://doi.org/10.36376/bmj.v7i2

remaja terhadap penyalahgunaan NAPZA di SMA Katolik disamakan Rantepao. Hal ini dapat dilihat pada tabel berikut.

Tabel 5.6

Analisis hubungan tingkat pengetahuan dan sikap remaja terhadap penyalahgunaan NAPZA di SMA Katolik disamakan Rantepao Toraja Utara, 2020.

\begin{tabular}{|c|c|c|c|c|c|c|c|}
\hline & \multicolumn{2}{|c|}{ Cukup+baik } & \multicolumn{2}{|c|}{ Kurang } & \multicolumn{2}{|c|}{ Total } \\
\hline & & $\mathrm{F}$ & $\%$ & $\mathrm{~F}$ & $\%$ & $N$ & $\%$ \\
\hline \multirow{3}{*}{ 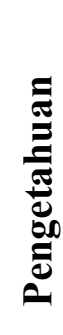 } & Cukup+baik & 87 & 87,0 & 0 & 0 & 87 & 87,0 \\
\hline & Kurang & 12 & 12,0 & 1 & 1 & 13 & 13,0 \\
\hline & Jumlah & 99 & 99,0 & 1 & 1 & 100 & 100 \\
\hline
\end{tabular}

\section{Sumber : Data Primer}

\section{PEMBAHASAN}

Berdasarkan hasil penelitian yang dilakukan di SMA Katolik disamakan Rantepao Toraja Utara didapatkan bahwa dari 100 responden, terdapat 87 responden $(87,0)$ dengan tingkat pengetahuan cukup+baik memiliki sikap cukup+baik. Menurut pendapat Notoatmodjo (2007), setelah seseorang mengetahui stimulus atau objek kesehatan, kemudian mengadakan penilaian atau pendapat terhadap apa yang diketahui. Proses selanjutnya diharapkan ia akan melaksanakan atau mempraktekkan apa yang diketahui atau disikapinya (dinilai baik). Menurut Notoatmodjo (2007), bahwa keilmuan tentang pendidikan dibagi menjadi yaitu: pendidikan secara formal yang diperoleh melalui pendidikan formal, pengetahuan yang didasarkan pada jenjang pendidikan rendah ke jenjang pendidikan yang lebih tinggi dan didapat dari ilmu pengetahuan melalui tingkat pembelajaran. Dan pengetahuan informal, pengetahuan yang didapat dari luar lingkup pendidikan. didapat melalui media elektronik (TV, radio atau alat elektronik lainnya) dan media massa (koran, majalah atau buku-buku pelajaran) maupun dari orang lain yang memberikan informasi tentang pengetahuan. Menurut Attkinson dijelaskan dalam Sunaryo (2004) salah satu fungsi sikap adalah fungsi pengetahuan, sikap membantu individu untuk memahami dunia, yang membwa keteraturan terhadap bermacammacam informasi yang perlu diasimilasikan dalam kehidupan sehari - hari. Setiap individu memiliki motif untuk ingin tahu, ingin mengerti dan ingin mendapat pengalaman dan pengetahuan. Menurut asumsi peneliti responden yang memiliki tingkat pengetahuan cukup+baik dan sikap memiliki sikap yang cukup+baik hal ini dikarenakan responden memiliki pemahaman yang baik tentang NAPZA yang diperoleh melalui media massa seperti TV dan internet sehingga dengan mudah mengembangkan pengetahuannya. 
Dari hasil penelitian, didapatkan pula 12 responden (12\%) yang memiliki tingkat pengetahuan kurang baik dan memiliki sikap cukup+baik. Menurut pendapat Notoatmodjo (2007) bahwa pengetahuan bergantung pada paparan informasi mengenai suatu hal dan sikap adalah tanggapan berdasarkan hasil penalaran/pengolahan terhadap informasi serta keyakinan yang ada. Jadi hubungan pengetahuan dan sikap ditentukan oleh seberapa baik penelaran seseorang untuk memilih informasi mana yang benar dan mana yang tidak. Menurut Notoatmodjo (2003) yang dijelaskan dalam Arif (2008) bahwa faktor yang mempengaruhi sikap seseorang adalah pengaruh orang lain yang dianggap penting atau seseorang yang berarti khusus akan banyak mempengaruhi sikap kita; kebudayaan di mana kita hidup dan dibesarkan mempunyai pengaruh besar terhadap pembentukan sikap kita. Tanpa kita sadari, kebudayaan telah menanamkan garis pengaruh sikap kita terhadap berbagai masalah. Menurut Allport (1954) dijelaskan oleh Notoatmodjo (2007) bahwa sikap mempunyai 3 komponen pokok adalah: kepercayaan (keyakinan), ide, dan konsep terhadap suatu objek; kehidupan emosional atau evaluasi terhadap suatu objek; kecenderungan untuk bertindak. Dalam penentuan sikap yang utuh ini, pengetahuan, pikiran, keyakinan, dan emosi memegang peranan penting. Dimana sikap merupakan kesiapan untuk bereaksi terhadap objek di lingkungan sebagai suatu penghayatan terhadap objek. Menurut asumsi peneliti responden yang memiliki tingkat pengetahuan kurang dan memiliki sikap cukup+baik hal ini dapat dipengaruhi oleh pola pikir dan emosi seseorang, bagaimana orang/remaja tersebut mengolah atau mempersepsikan baik atau buruknya informasi yang diterima. Sikap seseorang dapat terbentuk karena adanya interaksi yang dialami oleh remaja tersebut, seperti ada pengaruh dari teman sebaya, guru dan orang tua.

Dari hasil penelitian didapatkan responden memiliki tingkat pengetahuan kurang baik dan memiliki sikap kurang baik ada 1 responden (1\%). Menurut pendapat Notoatmodjo (2007), pengetahuan merupakan domain yang sangat penting dalam membentuk suatu tindakan seseorang. Pengetahuan dapat menjadi dasar seseorang dalam bertindak, berperilaku, dan memutuskan sesuatu karena perilaku yang didasari oleh pengetahuan akan lebih langgeng dari pada perilaku tidak didasari pengetahuan. Sebagian besar pengetahuan manusia diperoleh melalui mata dan telinga. Pengetahuan atau kognitif merupakan domain yang sangat penting dalam membentuk tindakan seseorang (overt behaviour). Serta menurut Erfandi (2009) bahwa salah satu faktor yang mempengaruhi pengetahuan adalah informasi/media massa, info yang diperoleh baik pendidikan formal maupun non formal dapat memberikan pengaruh jangka pendek sehingga menghasilkan perubahan/peningkatan pengetahuan. Menurut asumsi peneliti responden yang memiliki pengetahuan kurang dan sikap kurang baik. hal ini dikarenakan responden kurang memperoleh informasi tentang NAPZA dari media massa dan pihak sekolah tidak memberikan penyuluhan mengenai NAPZA.

Berdasarkan hasil kuesioner pada tingkat pengetahuan, dari 100 responden ada 47 responden yang dapat menjawab dengan benar pertanyaan tentang efek dari narkoba. Menurut asumsi peneliti, hal ini dikarenakan responden hanya mengetahui secara umum mengenai NAPZA seperti pengertian, ciri-ciri pecandu dan istilah untuk pecandu. Dimana istilah ini sering digunakan dalam masyarakat. Sedangkan kuesioner pada sikap remaja, semua responden sangat setuju untuk menolak jika teman mengajak untuk mencoba NAPZA. Menurut 
asumsi peneliti hal ini dikarenakan responden sadar dan mengetahui bahaya dari narkoba.

Uji statistik yang digunakan adalah Chi Square dengan tabel $3 \times 3$ tetapi terdapat 5 sel yang nilai expected count kurang dari 5 yaitu 55,6\% sehingga dilakukan penggabungan sel pada kategori tingkat pengetahuan baik dan cukup menjadi satu yaitu baik+cukup, begitu pun dengan kategori untuk sikap baik dan cukup menjadi satu yaitu baik+cukup, sehingga tabelnya berubah menjadi $2 \times 2$ dan dilakukan uji alternatif Continuity correction. Dari hasil uji Contuinity correction diperoleh $\mathrm{X}_{\text {hitung }}^{2}=1,223$ dan $\mathrm{X}_{\text {tabel }}=3,841$. Hal ini menunjukkan $\mathrm{X}^{2}$ hitung $<\mathrm{X}_{\text {tabel, }}^{2}$ maka hipotesis nol (Ho) diterima dan Ha ditolak, artinya tidak ada hubungan antara tingkat pengetahuan dengan sikap remaja terhadap penyalahgunaan NAPZA di SMA Katolik disamakan Rantepao Toraja Utara. Menurut pendapat Allport (1954) dijelaskan oleh Notoatmodjo (2007) bahawa dalam penentuan sikap yang utuh, pengetahuan, pikiran, keyakinan, dan emosi memegang peranan penting. Menurut Erfandi (2009) bahwa pengetahuan sangat erat kaitannya dengan pendidikan dimana diharapkan seseorang dengan pendidikan tinggi, maka orang tersebut memiliki pengetahuan semakin luas. Menurut asumsi peneliti bahwa tidak adanya hubungan antara tingkat pengetahuan dengan sikap responden karena sikap seseorang tidak hanya dipengaruhi oleh pengetahuan tetapi pola pikir dan emosi. Dalam berpikir, komponen emosi dan keyakinan ikut bekerja untuk bertindak. Serta seperti yang kita ketahui bahwa sikap seseorang pertama - tama terbentuk dari keluarga, bagaimana orang tua dalam mendidik atau memberikan pendidikan pada anaknya maka itu akan mempunyai pengaruh besar terhadap sikap seorang anak.

\section{Simpulan}

\section{SIMPULAN DAN SARAN}

Dari hasil penelitian yang dilakukan terhadap 100 responden pada tanggal 6 Februari 2020, maka dapat disimpulkan bahwa Tingkat pengetahuan tentang penyalahgunaan NAPZA siswa/i SMA Katolik disamakan Rantepao Toraja Utara adalah tingkat pengetahuan dengan kategori cukup. Sikap siswa/i SMA Katolik disamakan Rantepao Toraja Utara terhadap penyalahgunaan NAPZA adalah sikap dengan kategori baik. Kesimpulan tidak ada hubungan antara tingkat pengetahuan dan sikap remaja tentang penyalahgunaan NAPZA di SMA Katolik disamakan Rantepao Toraja Utara.

\section{Saran}

Berdasarkan kesimpulan dari hasil penelitian tersebut diatas, maka peneliti dapat memberikan saran - saran sebagai berikut:

1. Bagi SMA Katolik disamakan Rentepao.Diharapkan sekolah dapat mengalakkan pendidikan tentang NAPZA atau memberikan penyulahan tentang bahaya NAPZA.

2. Bagi remaja khususnya siswa/i SMA Katolik disamakan Rantepao.Berusaha untuk lebih meningkatkan pengetahuannya tentang bahaya yang ditimbulkan oleh NAPZA yang diperoleh melalui media massa (televisi, internet) atau mengikuti penyuluhan tentang bahaya dari narkoba.

3. Bagi Institusi Pendidikan

Diharapkan hasil penelitian ini dapat digunakan sebagai sumber referensi pada institusi Sekolah Tinggi Ilmu Keperawatan (STIK) Stella Maris Makassar dan 
dijadikan dokumentasi ilmiah untuk merangsang minat peneliti selanjutnya, serta menambah wawasan bagi mahasiswa(i) tentang NAPZA.

4. Bagi masyarakat

Diharapkan hasil penelitian yang diperoleh dapat menjadi bahan informasi bagi masyarakat untuk meningkatkan pengetahuan tentang NAPZA dalam pencegahan penyalahgunaan NAPZA.

\section{DAFTAR PUSTAKA}

Afiatin, T. (2008). Pencegahan Penyalahgunaan Narkoba dengan Program Aji. Yogyakarta: Gadjah Mada University Press.

Arif, H. (2008). Sikap Attitude. Diambil 19 April 2009, dari http://ajangberkarya.wordpress.com/2008/10/13/sikap-attitude/

Cahyani, F. T. (2011, Juni 26). 3,6 Juta Penduduk Indonesia Salah Gunakan Narkoba. Okezone.

Erfandi. (2009). Pengetahuan Dan Faktor-Faktor Yang Mempengaruhi. Diambil 19 April 2009, dari

http://forbetterhealth.wordpress.com/2009/04/19/pengetahuan-dan-faktorfaktor-yang-mempengaruhi/

Himapid UNHAS. (2009). Perilaku Berisiko Mahasiswa. Diambil 19 April 2009, dari http://himapid.blogspot.com/2009/03/perilaku-berisiko-mahasiswa.html

Kurnia, H. P. (2009). Hubungan Tingkat Pengetahuan Remaja tentang Napza dengan Kecenderungan Penyalahgunaan Napza pada Remaja Kelas II di SMA Berbudi Yogyakarta. Skripsi. Stikes Yogyakarta.

Makassar Tv. (2011). Estimasi Pengguna Narkoba di Makassar. Diambil 21 Maret 2011, http://makassartv.co.id/index.php?option $=$ com_content\&view $=$ article\&id $=30$ 19:estimasi-pengguna-narkoba-di-makassar-capai-51000orang\& catid $=3$ :berita-umum $\&$ Itemid $=56$.

Notoatmodjo, S. (2003). Pendidikan Dan Perilaku Kesehatan. Jakarta: PT Rineka Cipta.

Notoatmodjo, S. (2007). Promosi Kesehatan dan Ilmu Perilaku. Jakarta: PT Rineka Cipta.

Sumiati. (2009). Kesehatan Jiwa dan Konseling. Jakarta: CV Trans Info Media.

Sunaryo. (2004). Psikologi untuk Keperawatan. Jakarta: EGC.

Tribun Timur. (2011). Makassar Gerbang Sindikat Narkoba Internasional. Diambil dari http://makassar.tribunnews.com/2011/08/23/bnn-makassar-gerbangsindikat-narkoba-internasional 